\title{
Distribuição espacial das características morfodinâmicas das praias arenosas da costa oceânica da Ilha de Santa Catarina, SC, Brasil
}

\author{
Ulisses Rocha de OLIVEIRA ${ }^{1}$, Rodrigo do Carmo BARLETTA ${ }^{2}$ \& Norberto Olmiro HORN FILHO ${ }^{3}$
}

1. Instituto de Ciências Humanas e da Informação, Universidade Federal de Rio Grande (ICHI-FURG), Campus Carreiros. Av. Itália, km 8, Bairro Carreiros, CEP 96203-900, Rio Grande, RS, Brasil. E-mail: ulisseslicke@yahoo.com.br.

2. CB\&I Brasil. Rod. José Carlos Daux, 8600, Sala 102, Bloco 3, CEP 88050-000, Florianópolis, SC, Brasil. rodrigo.barletta@cbi.com.

3. Departamento de Geociências, Universidade Federal de Santa Catarina (DGEO-UFSC). Campus Universitário Reitor João David Ferreira Lima, Bairro Trindade, CEP 88040-970, Florianópolis, SC, Brasil. E-mail: horn@cfh.ufsc.br.

Recebido em 09/2013. Aceito para publicação em 06/2014.

Versão online publicada em 12/08/2014 (www.pesquisasemgeociencias.ufrgs.br)

\begin{abstract}
Resumo - Este trabalho visa analisar a distribuição espacial das características morfodinâmicas das praias arenosas de enseada localizadas na costa oceânica da Ilha de Santa Catarina, SC, Brasil. A metodologia consistiu na compilação e agrupamento de dados derivados do monitoramento de perfis de praia, utilizando técnicas de estatística multivariada para uma matriz de 40 casos (perfis de praias) e 8 variáveis (parâmetros morfométricos). Baseada nesta matriz foi aplicada uma análise de agrupamento (Cluster) e uma análise de componentes principais $(P C A)$, utilizando a Variância Mínima como estratégia de agrupamento. Os resultados demonstram que estas praias podem ser divididas em três grupos: Grupo 1 - praias de areia fina de baixa energia hidrodinâmica; Grupo 2 - praias de areia fina de moderada a alta energia hidrodinâmica; Grupo 3 - praias de areia média a grossa de moderada a alta energia hidrodinâmica. Estes três grupos foram então relacionados a estágios morfodinâmicos da zona de surfe, mesmo estes podendo apresentar uma alta variabilidade. Praias do Grupo 1 apresentam principalmente o estágio refletivo, com menor energia hidrodinâmica; praias do Grupo 2 apresentam todos os estágios intermediários (terraço de baixa mar, banco e praia de cúspide, banco e praia rítmicos e banco e cava longitudinais) e o estágio dissipativo. Já praias do grupo 3 mostram alguns dos estágios intermediários, como banco e praia rítmicos e banco e cava longitudinais, mas podem apresentar características de praia refletiva devido à alta declividade da face praial.
\end{abstract}

Palavras chave: Praias de enseada, parâmetros morfométricos, estatística multivariada.

\begin{abstract}
SPATIAL DISTRIBUTION OF MORPHODYNAMIC CHARACTERISTICS OF SANDY BEACHES IN THE OCEANIC COAST OF SANTA CATARINA ISLAND, SC, BRAZIL. This work aims to analyze the spatial distribution of morphodynamic characteristics in headland-bay beaches located in the oceanic coast of Santa Catarina Island, SC, Brazil. The methodology consists in the compiling and in the grouping of data derived from the monitoring of beach profiles, using multivariate statistics techniques for a matrix of 40 cases (beach profiles) and 8 variables (morphometric parameters). Based on this matrix it was applied both a cluster analysis and a principal components analysis (PCA), using the minimum variance as a grouping strategy. The results show that these beaches may be divided in three groups: Group 1 - beaches of fine sand and lower hydrodynamic power; Group 2 - beaches of fine sand and moderate to higher hydrodynamic power; Group 3 - beaches of coarse sand and moderate to higher hydrodynamic power. These three groups were then related to a different morphodynamic stages in the surf zone, even having a high variability. Beaches of group 1 show mainly a reflective stage and the lower hydrodynamic power. Group 2 may show all intermediate stages as well as a dissipative stage. Group 3 may show an intermediate stage, but may also show characteristics of a reflective beach due to the slope of the beach face.
\end{abstract}

Key words: Headland-bay beaches, morphometric parameters, multivariate statistics.

\section{Introdução}

As praias arenosas oceânicas, entendidas como depósitos inconsolidados situados na interface atual entre o próprio oceano, a atmosfera e uma porção de terra (continente ou ilha), são ambientes altamente dinâmicos espacial e temporalmente, dominados pela hidrodinâmica, causada primeiramente pela ação das ondas, marés e correntes litorâneas. Dada sua alta dinâmica, considera-se importante a realização de siste- matizações e/ou classificações como forma de geração de inventários, mesmo que locais ou regionais, que possibilitem uma comparação em diversas escalas de análise. Algumas classificações são denominadas de modelos sequenciais de evolução morfológica, as quais são baseadas na análise de um ou diversos estágios ou estados morfodinâmicos. Wright \& Short (1984), por exemplo, afirmaram que praias arenosas oceânicas dominadas por ondas, sujeitas ao regime de micromaré, podem variar desde o estágio dissipativo ao refletivo, 
apresentando estágios intermediários, caracterizados por assembleias morfológicas e processos hidrodinâmicos peculiares.

Segundo Wright \& Short (1984), o estágio dissipativo é caracterizado pela alta energia de onda, com larga zona de surfe, composta por dois ou mais bancos. As ondas arrebentam longe da linha de costa, geralmente de maneira deslizante, e dissipam sua energia ao longo da zona de surfe, quebrando e reformando diversas vezes através dos vários bancos que caracterizam esse ambiente. Este possui elevado estoque sedimentar na porção subaquosa, baixa declividade e areias de granulometria fina a muito fina em todos os setores. O estágio refletivo, oposto do dissipativo, representa a baixa energia de onda (Wright \& Short, 1984). Este pode apresentar elevados gradientes na topografia da face praial, o que reduz sensivelmente a zona de surfe. 0 ponto de quebra das ondas ocorre praticamente na face praial e tende a prevalecer em áreas com pequena altura de onda na praia, na presença de sedimentos grossos e/ou após longos períodos de acresção. Os estágios intermediários podem ter tanto condições de praia dissipativa, durante as tempestades, e de praia refletiva, durante as calmarias, mas geralmente representam a transição entre os dois. São mais variáveis do ponto de vista morfológico que os extremos dissipativo e refletivo, devido à maior variação no clima de ondas e à própria ritmicidade morfológica da zona de surfe. Segundo Wright \& Short (1984), podem ser distinguidos quatro estágios intermediários: banco e cava longitudinal, banco e praia de cúspides, bancos transversais e terraço de baixa mar.

Short \& Masselink (1999) identificaram que em praias de enseada, as quais geralmente apresentam forma de arco assimétrico, diferenças quanto ao grau de exposição tornam as linhas de costa variáveis quanto à forma em planta, características morfodinâmicas e granulométricas. Estas diferenças podem estar relacionadas, entre outras, à presença de promontórios adentrando o mar, característica encontrada em linhas de costa rochosas com topografia costeira montanhosa. Utilizando a classificação de Wright \& Short (1984), Short (1999) identificou que uma praia de enseada pode contemplar num mesmo período diferentes estágios, dependendo do grau de exposição, desde refletiva, na porção mais abrigada, onde a altura de onda no sistema é maior que a altura de quebra na praia $\left(\mathrm{H}_{0}>\mathrm{Hb}\right)$ até dissipativa, na porção mais exposta, onde $\left(\mathrm{H}_{0}=\mathrm{Hb}\right)$. Segundo Short (1999), nestes locais as praias refletivas ocorrem em áreas fortemente compartimentadas e em zonas protegidas por promontórios, o estágio intermediário bancos transversais desenvolve-se em porções protegidas de longas praias, as chamadas zonas de sombra, e em enseadas moderadamente abrigadas. Já o estágio intermediário com banco e cava longitudinal ocorre na porção mais retilínea da praia. Na porção mais exposta das praias de enseada, quando a deriva litorânea é compartimentada por obstáculos, podem ocorrer estágios dissipativos.

O objetivo deste trabalho é analisar a distribuição espacial das características morfodinâmicas das praias de enseada da costa oceânica da Ilha de Santa Catarina, $\mathrm{SC}$, Brasil, as quais ocorrem intercaladas com promontórios e pontais rochosos dominantemente graníticos. Para tal foram analisadas características granulométricas, morfológicas e hidrodinâmicas. A análise integrada destes dados possibilitou relacionar agrupamentos, denominado de tipo de praia, a uma classificação morfodinâmica predominante, utilizando Wright \& Short (1984), Short (1999) e Short \& Masselink (1999) para cada trecho ou agrupamento de praia analisado.

\section{2 Área de estudo, materiais e métodos}

\section{1 Área}

A área de estudo abrange praias da Ilha de Santa Catarina (Fig. 1), localizada na costa central do Estado de Santa Catarina, sul do Brasil, entre as latitudes

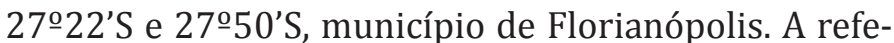
rida ilha possui $55 \mathrm{~km}$ de extensão e $18 \mathrm{~km}$ de largura máximas, com área de aproximadamente $423 \mathrm{~km}^{2}$ na forma alongada, na direção NE - SW. Neste trabalho, considera-se como a costa oceânica da Ilha de Santa Catarina o trecho situado na margem leste e norte da ilha, mais expostas à ação marinha, desconsiderando as margens da Baía Norte e da Baía Sul.

A Ilha de Santa Catarina é uma ilha costeira, cujos traços geomorfológicos assemelham-se aos das áreas continentais próximas. Seu relevo é marcado pela associação de duas unidades geológicas maiores: elevações dos maciços rochosos que compõem o embasamento cristalino e áreas planas de sedimentação costeira (Caruso Jr., 1993). Ambas delineiam respectivamente as denominadas serras litorâneas e planície costeira, unidades geomorfológicas que caracterizam a paisagem local. As elevações dos maciços rochosos apresentam em geral aspecto de crista, dada sua posição alongada e o acentuado declive das encostas. Os maciços encaixam-se no contexto do soerguimento das serras do leste catarinense (Caruso Jr., 1993).

A área é atravessada em toda sua extensão por uma dorsal central (o Granito Ilha), com orientação NNE - SSW, sentido do "alinhamento cristalino regional" (Tomazolli et al., 2007), a qual apresenta dois compartimentos, um a centro-norte e um a sul. A dorsal ramifica-se lateralmente em esporões que podem continuar submersos ou emergir na forma de ilhas. Os divisores de água separam as pequenas bacias fluviais e planícies costeiras.

Segundo CECCA (1997), na Ilha de Santa Catarina distinguem-se três ambientes de planícies costeiras de acordo com o nível de energia ambiental a que estão sujeitos: setor Leste, submetido à atuação das ondas e ventos de alta energia provenientes do sul; setor Oeste, 
compreendendo as águas protegidas das baías Norte e Sul; e o setor Norte, de nível de energia intermediário, que é atingido pelos ventos e ondulações oriundas do norte e protegido dos ventos do sul pelas elevações da dorsal central. As planícies estão associadas ao desenvolvimento de tômbolos e arcos praiais alternados na costa Leste e arcos praiais alternados com esporões arenosos na costa Norte. As praias das baías Norte e Sul apresentam menores dimensões e ocorrem em maior número.

As praias arenosas representam 55,5 \% (88 km) do perímetro total da ilha. Possuem geralmente forma de arco praial em planta, com diferentes graus de curvatura, estando intercalados a promontórios e pontais rochosos, adjacentes às planícies costeiras expostas a diferentes direções de incidência de onda. Suas variações morfológicas estão associadas à dinâmica costeira, basicamente a interação entre processos meteorológicos (vento e pluviosidade) e oceanográficos (ondas, marés e correntes litorâneas).
As características meteorológicas locais são controladas pela atuação das massas Polar Marítima e Tropical Marítima do Atlântico, inseridas na região de clima temperado da categoria subquente (Nimer, 1989). A situação normal da circulação atmosférica da região é o domínio de um sistema semifixo de alta pressão com ventos de norte/nordeste, juntamente com o efeito local da brisa marinha. Periodicamente, o sistema é perturbado pela passagem de frentes frias originadas pela migração do Anticiclone Polar Móvel sobre a região de sudoeste para nordeste (Trucollo, 1998; Mariotti \& Franco, 2001). Os ventos predominantes são de norte/nordeste, enquanto os de sul são mais intensos.

Quanto à ação das ondas, Araújo et al. (2003) identificaram como características gerais ao longo do ano a alternância de ondulações de sul com período em torno de $12 \mathrm{~s}$ e vagas de leste com período de 8 s. Durante o outono-inverno as ondulações de sul prevalecem sobre as vagas de leste, no verão há um balanço entre elas e na primavera prevalecem as vagas de leste. Condições

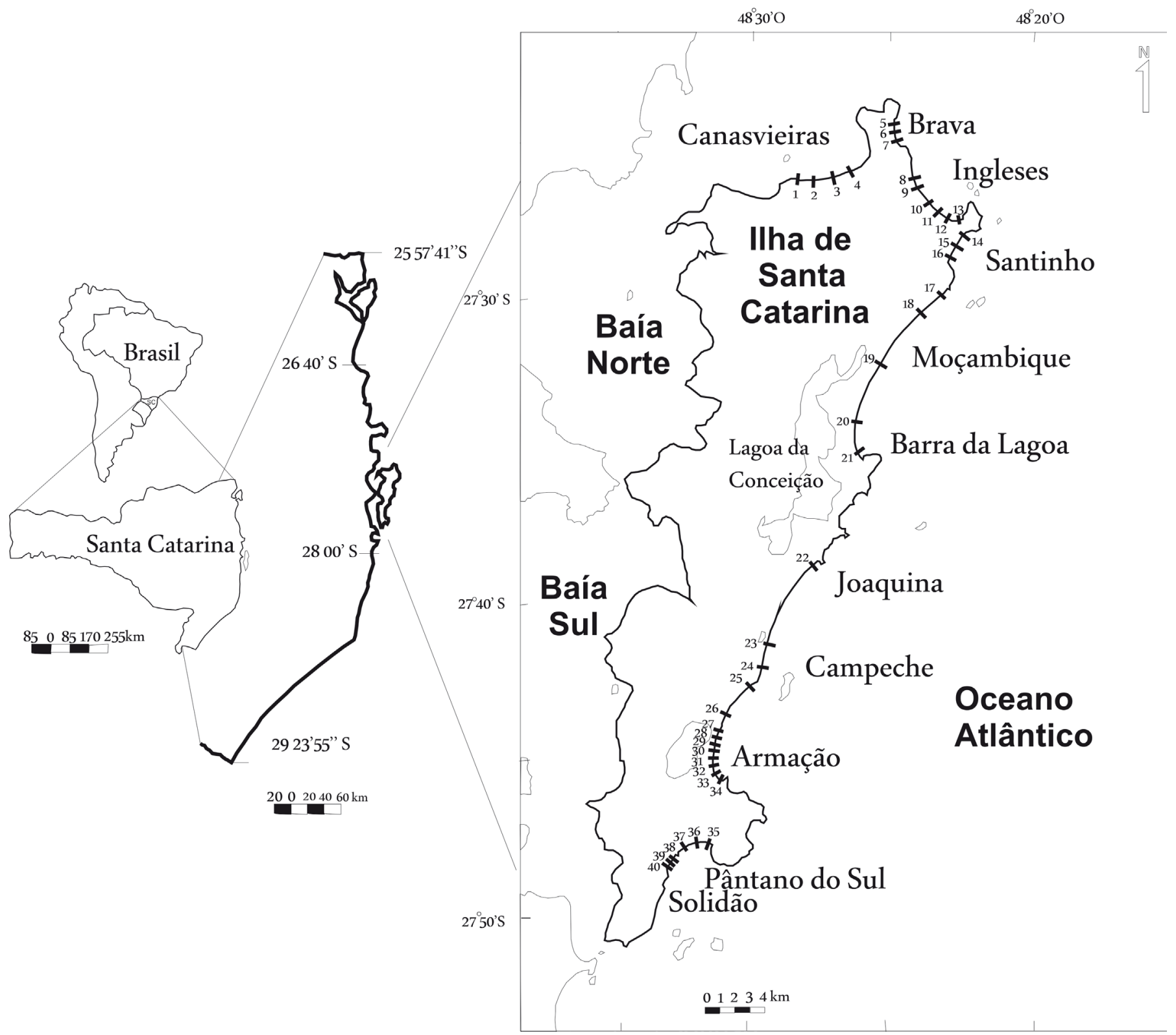

Figura 1. Mapa de localização da área de estudo destacando o litoral catarinense, à esquerda, e a costa oceânica da Ilha de Santa Catarina, à direita, com identificação dos 40 perfis analisados. 
de alta energia de onda geralmente provêm de ondulações de sul/sudeste, com períodos de pico acima de 11 s e ondas maiores que $4 \mathrm{~m}$ em águas profundas, podendo ser encontradas em todas as estações do ano. Estas características estão associadas à dinâmica meteorológica que atua sobre o Atlântico Sul.

A Ilha de Santa Catarina está sujeita a micro maré, com amplitude máxima de 1,2 m em condição de sizígia e regime semidiurno. As maiores variações do nível do mar ocorrem devido às marés meteorológicas. Mariotti \& Franco (2001) e Simó (2003) identificaram a ocorrência de empilhamento de água nas praias da Ilha de Santa Catarina entre 1991 e 2001. Segundo Simó (2003), este fenômeno está associado à combinação de forçantes atmosféricas e astronômicas, responsáveis pelos maiores empilhamentos de água na costa em todos os episódios registrados.

Diversos trabalhos envolvendo o monitoramento de perfis de praia foram realizados ao longo de praias arenosas do perímetro da Ilha de Santa Catarina, dentre os quais, Abreu de Castilhos (1995) na praia da Armação; Leal (1999) ao longo do sistema praial Moçambique - Barra da Lagoa; Torronteguy (2002) no sistema praial Joaquina - Morro das Pedras; Faraco (2003) na praia dos Ingleses; Oliveira (2004) no arco praial Pântano do Sul - Açores, Peixoto (2005) na praia do Santinho, Guttler (2006) na praia do Rio das Pacas e Schweitzer (2007) na praia Brava. Estes trabalhos diagnosticaram, de uma forma geral, diferenças no nível de energia de onda, de características morfodinâmicas e granulométricas em cada um destes ambientes praiais. Os levantamentos realizados por estes autores tiveram um período de cerca de um ano, com periodicidade mensal. A análise da variabilidade dos perfis com definição de períodos erosivos e deposicionais, juntamente com a análise granulométrica dos sedimentos possibilitou o cálculo de parâmetros morfométricos e adimensionais derivados do monitoramento praial, gerando uma base de dados. A maior parte dos autores apontados acima utilizou o modelo de Wright \& Short (1984) para classificar as praias quanto à característica morfodinâmica predominante. 0 uso desta metodologia como padrão possibilitou a integração desses dados, inicialmente com a construção de uma matriz de dados.

\subsection{Materiais e métodos}

\subsubsection{Matriz de dados}

Dados de 40 perfis de praia monitorados entre 1995 e 2008 foram utilizados (Fig. 1). A metodologia de obtenção destes dados consistiu na medição de perfis topográficos, coleta de sedimentos e observações visuais das condições hidrodinâmicas costeiras (altura e período de onda, correntes de deriva litorânea, presença de correntes de retorno e número de linhas de quebra de onda) com periodicidade aproximadamente mensal.
Estes dados foram coletados em 9 trabalhos de monitoramento, que abrangeram cerca de um ano cada.

Os perfis 1, 2, 3 e 4, situados na Praia de Canasvieiras, foram monitorados mensalmente durante onze campanhas por Oliveira et al. (2008a). Os perfis 5, 6 e 7 , situados na Praia Brava, foram monitorados mensalmente durante dezesseis campanhas por Schweitzer (2007). Os perfis 8, 9, 10, 11, 12 e 13, localizados na Praia dos Ingleses, foram monitorados mensalmente durante nove campanhas por Faraco (2003). Os perfis 14, 15 e 16, situados na Praia do Santinho, foram monitorados mensalmente durante doze campanhas por Peixoto (2005). Os perfis 17, 18, 19, 20 e 21, sistema praial Moçambique - Barra da Lagoa, foram monitorados mensalmente de doze a dezenove campanhas por Leal (1999). Os perfis 22, 23, 24, 25 e 26, localizados no sistema praial Joaquina - Morro das Pedras, foram monitorados mensalmente durante dez campanhas por Torronteguy (2002). Os perfis 27, 28, 29, 30, 31, 32, 33 e 34, situados na Praia da Armação, foram monitorados mensalmente durante quatorze campanhas por Abreu de Castilhos (1995). Os perfis 35, 36 e 37, localizados na Praia do Pântano do Sul, foram monitorados mensalmente durante treze campanhas por Oliveira (2004). Os perfis 38, 39 e 40, situados na Praia da Solidão ou do Rio das Pacas, foram monitorados mensalmente durante dezoito campanhas por Guttler (2006).

Com base em Short \& Hesp (1982) e Wright \& Short (1984) foram empregados diversos parâmetros morfométricos para este conjunto de dados, dentre os quais: diâmetro médio do grão (Mz - phi); grau de selecionamento das amostras (DpMz); declividade da face praial ( $\beta$ - graus); altura de arrebentação de onda (Hb metros); parâmetro adimensional ômega $(\Omega)$; variação da largura da praia (Yb - metros); coeficiente de variação da linha de costa (CVYb - \%); variação de volume subaéreo (VV - $\mathrm{m}^{3} / \mathrm{m}$ ).

O diâmetro médio do grão (Mz) (phi) e o grau de selecionamento do grão (Dp) (phi) foram obtidos através da coleta superficial de sedimentos na face da praia, peneiramento a seco das amostras e processamento estatístico. A escolha da face da praia para caracterização granulométrica das praias deu-se pelo fato de que em todos os perfis monitorados foi realizada pelo menos uma coleta superficial de sedimento neste subambiente praial.

A declividade da face da praia $(\beta)$ (graus) foi calculada para cada superfície usando o máximo e o mínimo espraiamento momentâneo, obtidos durante o monitoramento praial.

A altura significativa de arrebentação de onda na praia (Hb) (m) foi definida através da observação empírica da média de $1 /{ }_{3}$ das maiores ondas durante o período de medição dos perfis de praia, geralmente num período de 20 minutos, período em que se mediu também o período de onda (T) (s). A metodologia de observação visual utilizada foi baseada em Melo Filho (1991).

O parâmetro empírico adimensional ômega, pro- 
posto por Dean (1973) foi calculado pela fórmula $\Omega=$ Hb/Ws*T (Wright \& Short, 1984; Wright et al., 1985) considerando a altura da arrebentação (Hb), velocidade de sedimentação das partículas sedimentares (Ws) e período da onda (T) lograntes da quebra. A velocidade de sedimentação das partículas (Ws) foi calculada a partir do diâmetro médio do grão segundo a metodologia utilizada por Gibbs et al. (1971) corrigida por Baba \& Komar (1981). 0 valor do ômega indica se um grão de areia colocado em suspensão pela passagem de uma onda pode, ou não, se sedimentar durante o tempo em que o fluxo de água, induzido pela propagação da onda, é em direção a praia. Se isto acontecer, o sedimento vai se mover da zona de arrebentação para a praia, produzindo um perfil de acresção, mais refletivo. Em situação contrária, o grão ficando em suspensão por um período mais longo, tende a se deslocar em direção ao mar desenvolvendo, assim, um perfil de erosão, mais dissipativo (Calliari et al., 2003). Através do parâmetro ômega, Wright et al. (1985) relacionaram quantitativamente variáveis envolvidas no condicionamento morfodinâmico de cada estágio praial. Uma praia pode ser considerada dissipativa quando valores de ômega são maiores que seis $(>6)$, refletiva quando os valores de ômega são menores que um $(<1)$ e intermediária quando valores ficam entre 1 e 6.

A variação da largura da praia ou o índice de mobilidade do pós-praia (DpYb), representa o valor referente ao desvio padrão da posição ou largura média da linha de costa (Yb). O coeficiente percentual de variação da linha de costa (CV) foi obtido através de uma relação entre a largura média e o índice de mobilidade da praia (CV=Yb/DpYb).

Os dados de variação de volume (VV), calculados para a porção subaérea da praia, correspondem à área da seção transversal do perfil multiplicada por unidade de largura ( $1 \mathrm{~m}$ ), sendo expressos em $\mathrm{m}^{3} / \mathrm{m}$. Este dado possibilita a análise de períodos de acresção e erosão na porção subaérea da praia. Para definir a porção subaérea de cada praia foi estabelecido um nível de referência arbitrário (datum), obtido em relação ao nível do mar por ocasião de uma maré baixa de sizígia, de acordo com os dados das tábuas de maré da DHN para cada período de monitoramento.

\subsubsection{Integração dos dados}

Após a construção da matriz, composta por 8 variáveis (parâmetros) aplicadas para os 40 casos (perfis de praia), foram aplicadas técnicas de estatística multivariada, possibilitando uma análise integrada dos mesmos.

Inicialmente as variáveis foram submetidas à correlação de Pearson, utilizando o programa EXCEL, para analisar sua redundância. Num segundo momento as mesmas variáveis foram submetidas ao teste de Shapiro-Wilk (Shapiro \& Wilk, 1965), para testar sua normalidade, bem como analisados seus respectivos histogramas por meio do programa Estatística (Stata
12). Destas, apenas a variável altura de onda ( $\mathrm{Hb}$ ) foi considerada normal, com histograma simétrico. Pelo fato de apenas uma variável ser normal optou-se por submeter todas à logaritmização, visando normaliza-las. Em seguida, sobre esta matriz, foram aplicadas as técnicas de análise estatística multivariada, análise de agrupamento (Cluster Analysis), visando à distinção de tipos de praia, e análise de componentes principais (PCA) para avaliar a importância de cada variável (parâmetro) no referido agrupamento. O software utilizado para isto foi o MVSP/Plus (Kovach Computing Services).

A análise de agrupamento é usada pra descrever diversas técnicas estatísticas paramétricas, cujo propósito fundamental é classificar os valores de uma matriz de dados sob estudo em grupos discretos e relativamente homogêneos (baixa variação intragrupos), assim como distinguir descontinuidades ou heterogeneidades entre diferentes grupos (alta variação intergrupos) (Landim, 2000). Neste trabalho, buscou-se identificar similaridades entre diferentes perfis de praia, localizados em diferentes praias da Ilha de Santa Catarina. 0 processo de agrupamento foi aglomerativo, cujo critério básico da fusão entre um objeto e um grupo, ou entre dois grupos, é sempre o mesmo, ou seja, reunir grupos com maior similaridade. 0 cálculo desta similaridade escolhido foi o método de Variância Mínima (Log10).

Já a análise de componentes principais estabelece um conjunto de eixos vetoriais perpendiculares com base em uma matriz de semelhança. Estes eixos podem ser de componentes ou fatores. Cada componente corresponde a um autovetor dessa matriz. Após determinada a matriz de correlação entre m variáveis, são calculados " $m$ " autovetores, ou eixos fatoriais de comprimento $\lambda 1, \lambda 2, \lambda 3 \ldots \lambda \mathrm{m}$ decrescente em razão da sua contribuição à variância total dos dados. Estes comprimentos são os "m" autovetores ou "m" raízes latentes da matriz (Valentin, 2000). O primeiro eixo da análise de componentes principais representará a maior parte da variação dos dados. Graficamente, ela é resultante da rotação de uma nuvem de pontos dispostos no espaço multidimensional, de modo que o eixo mais longo seja a componente principal I (de maior variância), o segundo eixo mais longo a componente principal II e assim sucessivamente (Landim, 2000). De acordo com Davis (1986 apud Pereira, 2005) e Manly (1994 apud Pereira, 2005), o emprego da análise de componentes principais seria uma maneira de hierarquizar variáveis, através dos autovalores, de forma a ressaltar as variáveis que representam a maior variabilidade dos dados.

Por fim, os dados foram plotados sobre um mapa da Ilha de Santa Catarina. Durante a realização de cada monitoramento praial, cada um dos quarenta perfis foi georreferenciado com auxílio de um GPS. Com isto os resultados do agrupamento puderam ser espacializados. 


\section{Resultados}

A tabela 1 mostra os 8 parâmetros analisados para os 40 perfis de praia monitorados ao longo da costa oceânica da Ilha de Santa Catarina. As linhas representam os perfis de praia e as colunas os parâmetros morfométricos.

Pode-se observar preliminarmente na tabela 1 algumas relações entre parâmetros, tais como entre a declividade da face da praia, o diâmetro médio do grão $(\mathrm{Mz})$ e o grau de selecionamento das amostras (DpMz); entre a altura significativa de onda na praia e o parâmetro adimensional ômega. Por exemplo, em praias com diâmetro médio do grão tipo areia fina, as amostras coletadas geralmente são bem selecionadas e a declividade da face praial é baixa. Já a relação entre a altura significativa de onda na praia e o parâmetro adimensional ômega, deve-se ao fato deste utilizar a altura de onda como variável. No entanto, na aplicação da correlação de Pearson estas não representam valor tão elevado ao ponto de serem consideradas redundantes estatisticamente.

Tabela 1. Matriz de dados contendo os 8 parâmetros e os 40 casos (perfis). Mz (phi) - diâmetro médio do grão; DpMz - grau de selecionamento das amostras; $\beta$ (graus) - declividade da face praial; $\mathrm{Hb}(\mathrm{m})$ - altura de arrebentação de onda; $\Omega$ - parâmetro adimensional ômega; $\mathrm{DpYb}(\mathrm{m})$ - variação da largura da praia; CVYb \% - coeficiente de variação da linha de costa; VV (m³ $/ \mathrm{m})$ - variação de volume subaéreo.

\begin{tabular}{|c|c|c|c|c|c|c|c|c|c|}
\hline Perfis & Praia & $\mathrm{Mz}$ & $\mathrm{DpMz}$ & $\beta$ & $\mathrm{Hb}$ & $\Omega$ & $\mathrm{DpYb}$ & CVYb & $\mathrm{VV}$ \\
\hline P1 & Canasvieiras & 2,43 & 0,59 & 3,89 & 0,18 & 1,70 & 3,25 & 9,03 & 2,70 \\
\hline P2 & Canasvieiras & 2,20 & 0,37 & 3,87 & 0,18 & 1,27 & 2,45 & 8,55 & 1,74 \\
\hline P3 & Canasvieiras & 2,35 & 0,39 & 3,96 & 0,13 & 1,17 & 1,00 & 3,07 & 2,05 \\
\hline P4 & Canasvieiras & 2,44 & 0,34 & 7,31 & 0,10 & 1,05 & 1,83 & 4,59 & 1,96 \\
\hline P5 & Brava & 2,36 & 0,45 & 3,47 & 0,78 & 3,85 & 7,08 & 12,53 & 8,94 \\
\hline P6 & Brava & 2,30 & 0,47 & 4,37 & 0,71 & 3,52 & 13,52 & 26,84 & 15,23 \\
\hline P7 & Brava & 2,39 & 0,41 & 3,71 & 0,55 & 2,95 & 12,88 & 16,47 & 15,72 \\
\hline P8 & Ingleses & 2,23 & 0,29 & 2,88 & 0,76 & 3,00 & 11,11 & 16,10 & 14,10 \\
\hline P9 & Ingleses & 2,29 & 0,31 & 3,25 & 0,74 & 3,15 & 10,58 & 16,63 & 12,65 \\
\hline P10 & Ingleses & 2,30 & 0,36 & 3,95 & 0,46 & 2,44 & 11,60 & 22,17 & 8,05 \\
\hline P11 & Ingleses & 2,40 & 0,32 & 3,69 & 0,34 & 2,12 & 8,89 & 21,68 & 6,65 \\
\hline P12 & Ingleses & 2,37 & 0,33 & 3,57 & 0,35 & 2,06 & 5,35 & 10,53 & 5,87 \\
\hline P13 & Ingleses & 2,47 & 0,33 & 4,02 & 0,26 & 1,86 & 3,69 & 10,23 & 4,79 \\
\hline P14 & Santinho & 2,04 & 0,50 & 2,89 & 1,05 & 5,50 & 9,79 & 17,74 & 11,67 \\
\hline P15 & Santinho & 2,05 & 0,42 & 2,96 & 1,00 & 3,54 & 12,75 & 24,03 & 11,69 \\
\hline P16 & Santinho & 2,12 & 0,44 & 2,82 & 0,69 & 3,62 & 18,72 & 19,38 & 13,99 \\
\hline P17 & Moçambique & 2,34 & 0,39 & 5,00 & 0,85 & 3,38 & 9,32 & 21,18 & 18,19 \\
\hline P18 & Moçambique & 1,36 & 0,62 & 9,80 & 0,95 & 1,36 & 11,32 & 23,10 & 17,72 \\
\hline P19 & Moçambique & 0,69 & 0,64 & 9,00 & 1,00 & 1,09 & 21,02 & 67,80 & 30,20 \\
\hline P20 & Moçambique & 1,23 & 0,67 & 8,30 & 0,90 & 1,47 & 25,58 & 56,84 & 39,50 \\
\hline P21 & Barra da Lagoa & 2,21 & 0,54 & 5,70 & 0,40 & 1,90 & 10,74 & 22,85 & 15,10 \\
\hline P22 & Joaquina & 2,26 & 0,28 & 2,60 & 1,52 & 8,30 & 13,46 & 16,78 & 20,11 \\
\hline P23 & Campeche & 1,94 & 0,44 & 3,82 & 1,12 & 4,53 & 5,45 & 11,07 & 3,48 \\
\hline P24 & Campeche & 2,09 & 0,38 & 2,26 & 0,73 & 3,78 & 10,40 & 22,51 & 6,47 \\
\hline P25 & Campeche & 2,09 & 0,40 & 2,50 & 0,81 & 3,16 & 21,00 & 24,13 & 13,17 \\
\hline P26 & Morro das Pedras & 1,16 & 0,53 & 5,78 & 1,25 & 1,67 & 7,63 & 17,50 & 11,65 \\
\hline P27 & Armação & 0,20 & 0,38 & 15,00 & 1,31 & 1,06 & 10,00 & 16,39 & 27,10 \\
\hline P28 & Armação & 0,23 & 0,50 & 10,00 & 1,04 & 0,87 & 7,50 & 20,27 & 12,20 \\
\hline P29 & Armação & 0,30 & 0,31 & 10,00 & 1,01 & 0,85 & 7,50 & 25,00 & 11,50 \\
\hline P30 & Armação & 0,42 & 0,47 & 15,00 & 0,93 & 0,89 & 7,00 & 17,07 & 11,20 \\
\hline P31 & Armação & $-0,25$ & 0,44 & 8,50 & 0,91 & 0,58 & 10,00 & 26,31 & 3,32 \\
\hline P32 & Armação & 1,69 & 0,52 & 8,00 & 0,73 & 1,54 & 11,00 & 28,94 & 3,31 \\
\hline P33 & Armação & 2,69 & 0,33 & 5,00 & 0,66 & 3,72 & 12,00 & 34,28 & 4,35 \\
\hline P34 & Armação & 2,78 & 0,33 & 5,00 & 0,50 & 2,96 & 3,75 & 38,07 & 1,48 \\
\hline P35 & Pântano do Sul & 2,63 & 0,39 & 2,38 & 0,23 & 1,34 & 7,31 & 13,41 & 3,95 \\
\hline P36 & Pântano do Sul & 2,29 & 0,36 & 4,23 & 0,56 & 2,32 & 6,06 & 15,03 & 4,96 \\
\hline P37 & Pântano do Sul & 2,20 & 0,41 & 3,73 & 0,77 & 3,34 & 11,37 & 19,93 & 9,79 \\
\hline P38 & Solidão & 2,52 & 0,41 & 4,57 & 0,75 & 5,32 & 10,31 & 34,79 & 6,67 \\
\hline P39 & Solidão & 2,60 & 0,40 & 4,09 & 0,74 & 5,21 & 7,59 & 25,59 & 3,01 \\
\hline P40 & Solidão & 2,60 & 0,40 & 3,49 & 0,74 & 5,40 & 9,16 & 20,13 & 7,07 \\
\hline
\end{tabular}


Primeiramente foi aplicada a análise de agrupamento (Cluster), utilizando a variância mínima como estratégia de agrupamento (Fig. 2). Utilizando uma linha de corte em 12, identificou-se a existência de três grupos principais, denominados Grupo 1, Grupo 2 e Grupo 3.

0 Grupo 1 é representado pelos perfis $1,2,3$, 4; o Grupo 2 é representado pelos perfis 5, 6, 7, 8, 9, 10, 11, $12,13,14,15,16,17,21,22,23,24,25,32,33,34,35$, $36,37,38,39$ e 40 enquanto o Grupo 3 é representado pelos perfis 18, 19, 20, 26, 27, 28, 29, 30 e 31. Ressalta-se que a escolha da linha de corte é fundamental, pois esta pode definir conforme o dendrograma (Fig. 2) a presença de dois grandes grupos com linha de corte acima de 32, cinco grupos com linha corte em 7, ou ainda um maior número de agrupamentos com linha de corte abaixo de 5. Por exemplo, com linha de corte em 7 , os grupos 2 e 3 podem subdivididos, onde no Grupo 2 , parte representa praias de areia fina de moderada energia hidrodinâmica (perfis 10, 11, 12, 13, 21, 33, 34, $35,36)$ e a outra parte praias de alta energia hidrodinâmica (perfis 5, 6, 7, 8, 9, 14, 15, 16, 17, 22, 25, 37). Já para o Grupo 3, usando este mesmo corte, pode se identificar praias de areia média (areias finas e grossas) (perfis 18, 20,26) e praias de areia grossa (perfis $27,28,29,30$ e 31). No entanto, devido a algumas limitações desta linha de corte, visto que nem todos os perfis se encaixaram na subdivisão, optou-se pela escolha dos três agrupamentos.

Posteriormente aplicou-se a análise de componentes principais, chamada PCA (Fig. 3) utilizando também a variância mínima como estratégia de agrupamento. A técnica possibilitou identificar quais parâmetros foram responsáveis pelo agrupamento.

A figura 3 mostra pontos distribuídos num diagra- ma de dispersão com 40 casos, no qual os eixos são as duas componentes mais importantes (eixo 1 e eixo 2) e mostram o relacionamento entre os casos condicionados pelas variáveis medidas. Neste caso, o eixo mais longo, o horizontal, é o componente principal I (de maior variância) e o segundo eixo mais longo, o vertical, é o componente principal II. Os três grupos distinguidos na figura 3 puderam ser distribuídos segundo as duas componentes principais apresentadas.

0 Grupo 1 ficou à direita da figura, na porção inferior do eixo 2, devido principalmente à menor energia hidrodinâmica (Hb), mobilidade da praia (Yb, CVYb, VV) e também do parâmetro ômega. 0 Grupo 2 ficou na porção mais central do gráfico, representando a maior parte dos 40 casos analisados, mas na porção superior deste, indicado possivelmente pelo maior valor no parâmetro ômega. Já o Grupo 3 ficou na porção inferior esquerda, associado ao maior diâmetro médio do grão $(\mathrm{Mz})$ e maior declividade, apresentando também alta energia hidrodinâmica $(\mathrm{Hb})$ e alta mobilidade sedimentar (Yb, CVYb, VV).

Baseado na interpretação dos dados pode-se afirmar que todas as variáveis utilizadas tiveram sua relevância na distinção desses três grupos ou tipos de praia. 0 diâmetro médio do grão $(\mathrm{Mz})$ é o parâmetro que define os padrões do grau de selecionamento (DpMz), velocidade de sedimentação das partículas (Ws), utilizado no cálculo do parâmetro ômega, e declividade da face praial $(\beta)$. Por exemplo, praias com areia fina tendem a apresentar bom grau de selecionamento, baixa velocidade de sedimentação das partículas e baixa declividade da face praial, podendo apresentar alto valor de ômega $(\Omega)$ dependendo a energia hidrodinâmica $(\mathrm{Hb})$. Quanto à variabilidade morfológica da porção subaérea, em geral houve boa relação entre os

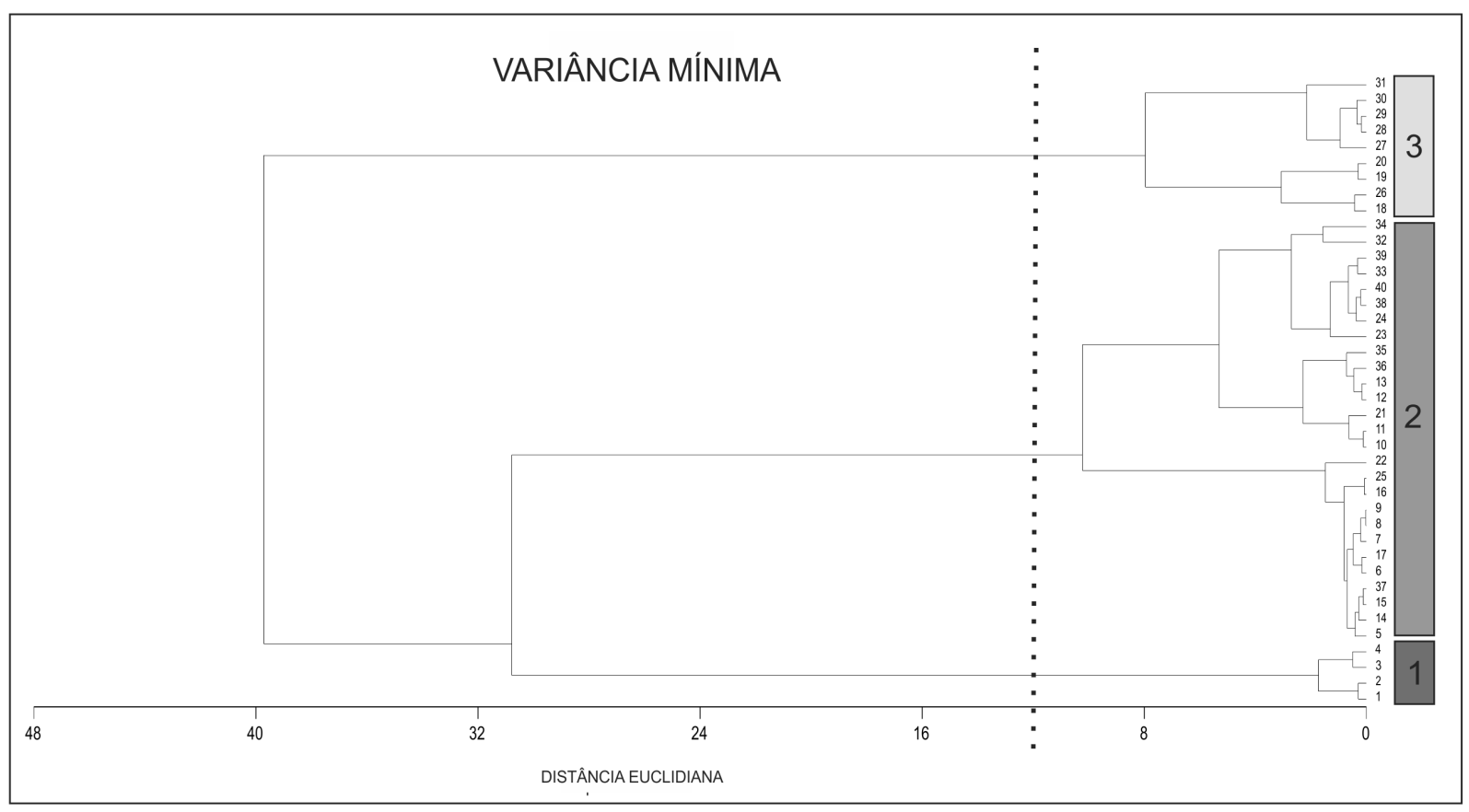

Figura 2. Dendrograma com o agrupamento dos 40 perfis utilizando a linha de corte em 12 e a identificação dos três grupos: Grupo 1, Grupo 2 e Grupo 3. 
parâmetros obtidos da medição de perfis transversais à praia $(\mathrm{DpYb}, \mathrm{CVYb}$ e VV), principalmente a variação largura da praia (DpYb) e a variação de volume (VV). Praias com maior diâmetro médio do grão, e consequentemente com maior inclinação, estão entre as praias que apresentam maiores valores de variação de volume (VV). Já aquelas compostas de areia fina, mais planas, em geral apresentam maiores valores de variação da linha de costa (DpYb) e maiores coeficientes de variação da linha de costa (CVYb), exceto as praias mais estreitas. Geralmente as praias mais expostas, isto é, aquelas com maior tamanho de quebra de onda, têm maior variação dos parâmetros morfométricos $(\mathrm{DpYb}$, CVYb e VV). Estabelecendo-se um diálogo entre energia de onda e mobilidade sedimentar, geralmente se espera que praias mais expostas tenham maior mobilidade, que pode ser visto como causa da separação do Grupo 1.

Com base nos parâmetros analisados para os quarenta perfis de praia, análise de cluster, a qual indicou três grupos de tipos de praia, e análise de componentes principais, a qual indicou relações entre as variáveis, pode-se inferir que as praias oceânicas da Ilha de Santa Catarina estão dispostas em três grupos principais:

Grupo 1: Possuem baixa altura de quebra de onda na praia, sendo abrigadas da alta energia das ondas pela presença das elevações da dorsal central da Ilha de
Santa Catarina. 0 Grupo 1 distinguiu as praias da costa leste das praias da costa norte da Ilha de Santa Catarina (Fig.4). São as praias mais estáveis morfologicamente dentre as analisadas por serem as mais abrigadas da energia marinha pelos promontórios dentre as praias analisadas. São compostas de areias finas bem selecionadas.

Grupo 2: Praias compostas geralmente de areia fina bem selecionada com baixa a moderada declividade na face praial, expostas à moderada e à alta energia das ondas. Englobam todas as praias de areia fina da costa leste da Ilha de Santa Catarina, sujeitas a moderada e alta energia de onda e moderada a alta variabilidade morfológica. Abrangem desde áreas mais expostas à ação da alta energia de onda, mas também praias sob a influência dos promontórios rochosos situados mais a leste, considerados tômbolos ou pseudotômbolos (Fig. 4) algumas com características semelhantes às praias do Grupo 1, caso dos perfis 12 e 13.

Grupo 3: Praias compostas de areia média a grossa expostas à moderada e à alta energia das ondas. Segundo a análise de componentes principais, esse grupo decorre da maior variabilidade morfológica, do maior diâmetro médio do grão e alta declividade na face praial. Estas se restringem a porção central de duas enseadas, em áreas afastadas dos promontórios que mais influenciam na geometria dos referidos arcos (Fig. 4).

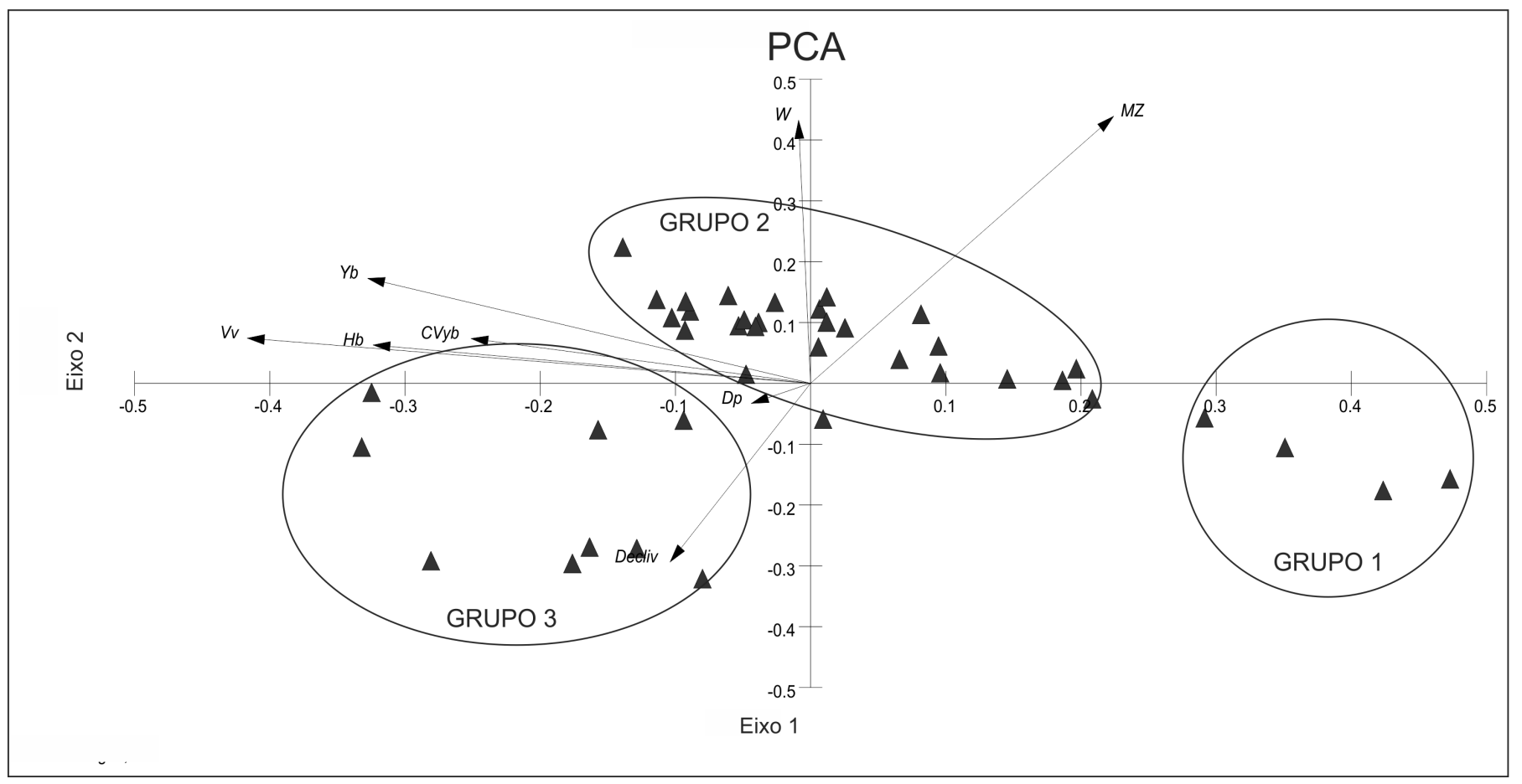

Figura 3. Análise de Componentes Principais (PCA) para a matriz de dados utilizada, distinguindo os três grupos ou tipos de praia. 

$48^{\circ} 20^{\circ} \mathrm{O}$

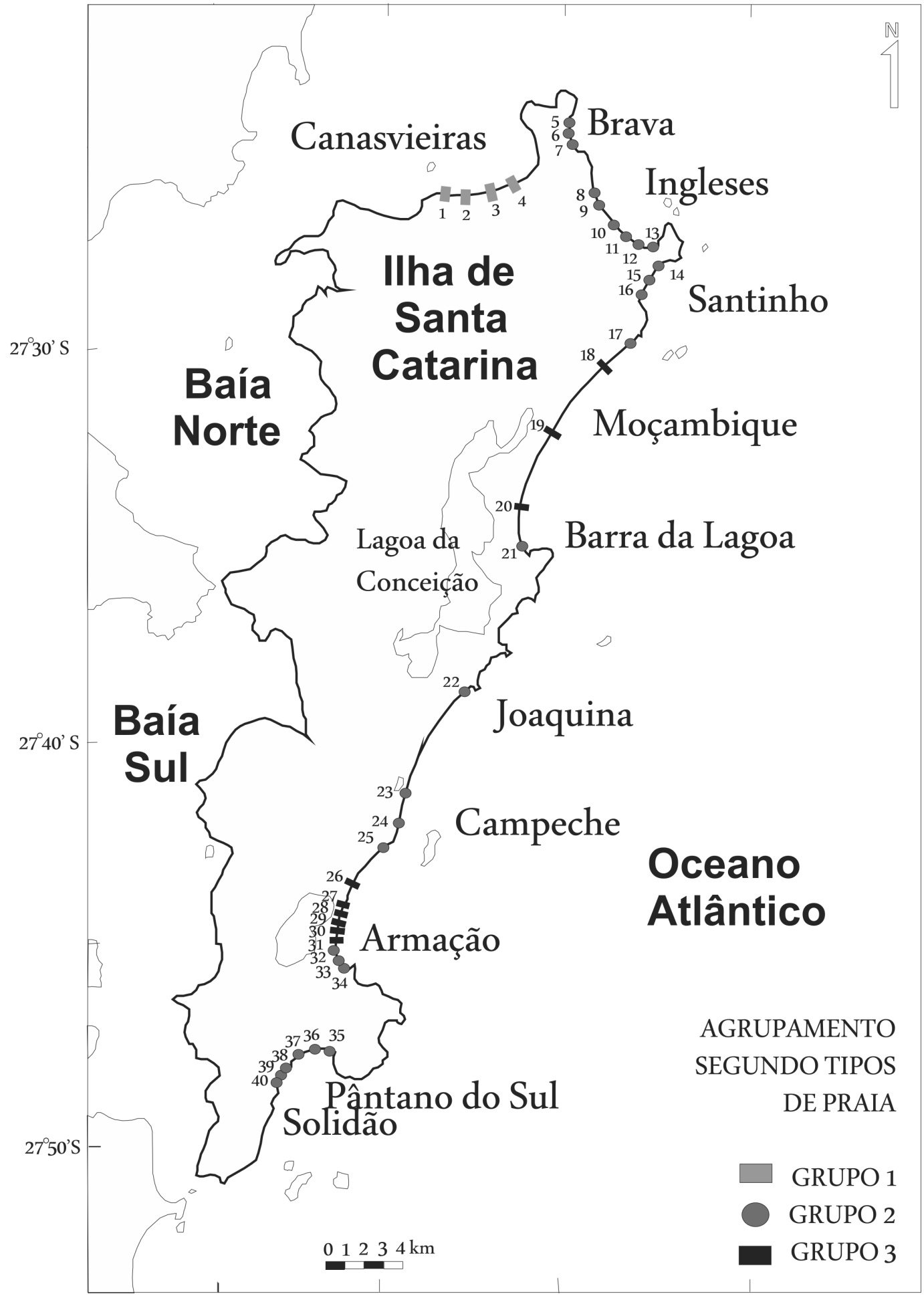

Figura 4. Mapa da costa oceânica da Ilha de Santa Catarina, com a localização dos 40 trechos analisados (perfis de praia) e a distinção dos três grupos de praia. Grupo 1 - Praia de areia fina de baixa energia hidrodinâmica; Grupo 2 - Praias de areia fina de moderada a alta energia hidrodinâmica; Grupo 3 - Praias de areia grossa com moderada a alta energia hidrodinâmica.

\section{Discussão}

\subsection{Estágios morfodinâmicos dos três tipos de praia}

Durante a realização dos trabalhos anteriores, cada perfil de praia monitorado foi classificado através de metodologia sugerida nos trabalhos de Short \& Hesp (1982), Wright \& Short (1984) e Wright et al. (1985). Tratam-se de métodos de classificação de praias em re- lação a forma da praia e à dinâmica de variações morfológicas, levando em consideração parâmetros como o ômega adimensional e parâmetros morfométricos. Com esta metodologia é possível classificar uma praia como dissipativa, refletiva ou intermediária.

O objetivo deste item é retomar tal classificação de uma forma integrada aos 40 perfis e, além disso, relacionar os 40 perfis e os três agrupamentos a classificação de estágios morfodinâmicos para praias de enseada apresentado por Short (1999) e Short \& Masselink (1999). 


\subsubsection{Praias dissipativas}

No litoral centro-sul catarinense, onde há um alinhamento cristalino regional (Azimute 15 graus $\mathrm{N}$ ) e uma plataforma continental relativamente estreita e profunda (Plataforma de Florianópolis), setores norte de algumas praias, como Santinho (perfil 14) e Joaquina (perfil 22) (Fig. 5A), de areias finas e expostas à alta energia hidrodinâmica, apresentaram valor de ômega que as classificam como dissipativas. Praias um pouco mais abrigadas pela presença de promontórios rochosos, como trechos das praias da porção norte do Moçambique (perfil 17) e do Campeche (perfil 25), com valor de ômega de praia intermediária, exibem também características de praia dissipativa, pois estão expostas as grandes ondulações de SSE, embora estejam parcialmente abrigadas das ondas provenientes de ENE. Apenas as praias do Grupo 2 podem ser dissipativas. Estas, inclusive, são fornecedoras de sedimento para a planície através da ação eólica, que pode gerar dunas de grande esbelteza.

O estágio praial em questão ocorre de uma combinação de fatores para a área de estudo, como a presença de areia fina, a exposição da praia às grandes ondulações, descritos acima, mas também a ação dos chamados "efeitos finais" (Short \& Masselink, 1999), gerados pela presença dos promontórios rochosos que, nos casos referidos, ampliam a largura da zona de surfe (Fig. 6). Algumas praias podem apresentar características de praia intermediária, como banco e cava longitudinal, banco e praia de cúspides, e, sob a ação dos efeitos finais, no caso promontórios rochosos barrando a deriva resultante de sul pra norte, tornarem-se dissipativas. Podem, por vezes, apresentar menor altura de arrebentação de onda ( $\mathrm{Hb})$ do que as intermediárias, pois a grande deposição sedimentar durante tempestades pode implicar a perda de energia de onda por fricção na antepraia rasa durante a ação da baixa a moderada energia hidrodinâmica.

\subsubsection{Praias refletivas}

Segundo o parâmetro ômega, praias refletivas podem ter baixa e alta energia de onda, visto este considerar a proporcionalidade entre energia de onda (altura da arrebentação e período de onda), com a velocidade de sedimentação das partículas sedimentares, que é diretamente relacionada ao diâmetro médio do grão.

Praias refletivas de baixa energia hidrodinâmica ocorrem em áreas abrigadas da ação direta da alta energia de onda pelos promontórios rochosos. Na zona de surfe, há ausência de bancos arenosos definidos e a ocorrência de um prolongamento do perfil subaéreo, geralmente composto de areia fina. Para a área de estudo, a linha de costa ocorre em geral na orientação leste-oeste (E-W), ou mesmo em sentido oposto as praias mais expostas da região da Plataforma de Florianópolis. Neste caso, quando há alta energia de onda ao largo, proveniente de E-ENE ou E-SE durante as chamadas "lestadas", ondas pequenas, geralmente abaixo de 0,5 metros, incidem nessas praias, podendo gerar um terraço de baixa mar. Para a área de estudo, correspondem às praias do Grupo 1 (Perfis 1 a 4), restritas a praia de Canasvieiras (Fig. 5F), costa norte da Ilha de Santa Catarina. Alguns perfis da costa leste podem apresentar tais características, como os perfis 12 e 13, extremo sul da praia dos Ingleses.

Já praias com areias grossas e alta energia de onda, embora apresentem ômega de praia refletiva, e mesmo alta declividade na face da praia, podem ser classificadas como intermediárias se levada em consideração a morfologia dos bancos arenosos. Estas praias ocorrem nas porções centrais de enseadas expostas à alta energia (perfis 18, 19, 20, 26, 27, 28, 29, 30 e 31), correspondendo às praias do Grupo 3 . Esta contradição deve-se ao fato destas apresentarem após a alta declividade na face praial, uma cava, relativamente profunda, seguida por um banco longitudinal (praia intermediária com banco e cava longitudinal) ou rítmico (praia intermediária com banco e praia de cúspide), não unido à praia subaérea. Durante a maioria dos perfis mensurados estes se restringem a praia subaérea e no máximo até o início da primeira cava, uma limitação da maioria dos trabalhos anteriores, dentre os quais se incluem os realizados pelos autores deste trabalho, os quais se restringiram a porção subaérea da praia, por questão de logística. Segundo Calliari et al. (2003), comumente nestas praias com areia média a grossa e alta energia de onda, as ondas dissipam energia no banco, se reformam na cava mais profunda e, ao atingir a face, condições refletivas predominam. Após grandes ressacas, as praias intermediárias que estejam compostas por areia grossa ficam com estágio morfodinâmico refletivo porque o banco externo é erodido, por ter tido que se ajustar à grande altura de quebra de onda durante o evento de alta energia antecedente. Quando o mar baixa, só há quebra de onda na face praial. Com a persistência da baixa a moderada energia (deposição), o banco externo tende a se formar novamente, conforme a disponibilidade sedimentar.

\subsubsection{Praias intermediárias}

Praias intermediárias predominam ao longo da costa oceânica da Ilha de Santa Catarina. Embora sejam altamente variáveis espaço-temporalmente, algumas tendências dos quatro tipos de praia intermediária segundo a classificação de Wright \& Short (1984) podem ser descritas.

Praias intermediárias com banco e cava longitudinal (BCL) são expostas a ação direta de ondas provenientes tanto de SSE quanto de ENE, havendo processos de deriva litorânea, responsável pela morfologia dos bancos. A linha de costa nestes segmentos é praticamente retilínea. Praias com bancos e cavas longitudinais compostas por areia fina apresentam baixa de- 
clividade, podendo ter tendência ao estágio dissipativo (Perfis 14, 15, 17, 22, 25) (Fig. 5B), correspondendo as praias do Grupo 2. Praias com face refletiva, descritas no item anterior, também desenvolvem com frequência um banco longitudinal na zona de surfe, tais como os perfis 18, 19, 20, 27, 28, 29, 30 e 31 (Grupo 3). Os perfis 23 e 24 têm aspectos que se enquadram a este estágio. Lembrando que quando da permanência da baixa energia estes perfis podem apresentar outros estágios morfodinâmicos intermediários, variação que ocorre também com os demais.

Praias intermediárias com banco e praia de cúspide (BPC), também conhecidas como praias rítmicas (Fig. 5C), ocorrem em áreas com granulometria variável e dependem do clima de onda, sendo expostas a diferentes direções de onda atuantes na área de estudo. Os perfis 5, 6, 7, 8, 9, 36, 37, 38, 39 e 40 apresentam recorrentemente essa característica, em especial nos períodos em que estão sujeitos a moderada e alta energia. Os perfis15, 16, 23, 24, 30, 31 também podem apresentar tal característica, mas não necessariamente quando da alta energia para o referido local.

Praias intermediárias com bancos transversais (BT) ocorrem onde a linha de costa apresenta maior diferença entre o ângulo de incidência de ondas e a orientação da linha de costa que os estágios intermediários descritos anteriormente, mas que, durante o processo de transformação em águas rasas, os mecanismos de refração e difração sejam eficazes, possibilitando com que as ondas quebrem com incidência pouco oblíqua, formando várias células de correntes de retorno alternadas aos bancos transversais (Fig. 5D). Estas também estão associadas aos períodos de swell de moderada a baixa energia nas demais praias expostas. Nos estágios praiais junto às cúspides e megacúspides se desenvolvem condições dissipativas e junto aos embaiamentos ou pequenas baías predominam condições refletivas. $\mathrm{Na}$ área de estudo, geralmente ocorrem em áreas com linha de costa com certa curvatura em planta, caso dos perfis $5,6,7,8,9,10,11,21,32$, 33 e 34, 36, 37, 38, 39 e 40, mas como se esperar de praias intermediárias, em algumas delas após períodos de alta energia no local enquanto em outros durante períodos de baixa energia no local. Correspondem basicamente a praias do Grupo 2 .

Praias intermediárias com terraço de baixa mar (TBM) se desenvolvem em áreas abrigadas por promontórios rochosos (Fig. 5E) ou também em praias expostas durante períodos de baixa energia persistentes na costa. Apresentam cúspides praiais com pequeno espaçamento entre as cristas e pequenas dunas frontais. Ressalta-se que a tendência para o comportamento geral é a de baixa energia, mas quando sujeita a significativos eventos excepcionais, por isso uma praia intermediária. Desenvolvem tal estágio com frequência os perfis $10,11,12,13,21,32,33,34$ e 35 . 0 perfil 35 é um exemplo de estágio morfodinâmico terraço de baixa mar (Oliveira, 2004; Oliveira et al., 2008b), embora o valor de ômega classifique-o como refletivo, com baixa energia e areias finas. Klein \& Menezes (2001) e Klein (2004) classificaram praias da costa catarinense compostas de areia fina, com baixa declividade e baixa energia de onda, como dissipativas/intermediária com terraço de baixa mar. Klein (2004) baseou-se na baixa declividade da praia e na ação de ondas de maior energia sobre bancos situados mar adentro, gerados pelos processos de transporte sedimentar citados anteriormente, para essa mesma classificação. No presente estudo, as praias planas de baixa energia foram classificadas como intermediária com terraço de baixa mar, pois embora durante alguns períodos de alta energia de ondas provenientes de E-ENE podem ter moderada a alta energia de onda, durante a maior parte do tempo comportam-se como praias abrigadas com maior estabilidade morfológica tendo apenas uma quebra de arrebentação de onda, considerando que se aproximam mais das praias refletivas de baixa energia (4.2.2) do que das praias dissipativas (4.2.1).

A figura 6 apresenta a classificação de estágios morfodinâmicos para praias de enseada apresentado por Short (1999) e Short \& Masselink (1999), descrita brevemente na introdução do trabalho. Trata-se de uma representação em planta que ilustra os seis estágios morfodinâmicos propostos por Wright \& Short, (1984) em uma praia de enseada. Todavia isso não quer dizer que em toda praia de enseada todos os estágios coexistam. Na figura 6 os estágios morfodinâmicos para praias oceânicas de micromaré são espacializados conforme sua posição mais recorrente, considerando diferenças da energia de onda em mar aberto (Ho) e nas proximidades da quebra de onda junto à praia $(\mathrm{Hb})$. 0 estágio dissipativo (ou próximo de) é comumente observado na porção superior da referida enseada, o estágio refletivo na porção inferior e os estágios intermediários na porção central, sendo as condições mais energéticas aquelas mais próximas à porção superior da enseada, onde a diminuição de energia de onda na praia em relação a condições de mar aberto é menor $(\mathrm{Ho}=\mathrm{Hb})$ do que na porção inferior da enseada $(\mathrm{Hb}<<$ Ho), onde a condição hidrodinâmica nas proximidades da quebra da onda é menos energética.

Sobre este modelo esquemático foram colocadas as posições mais recorrentes dos três agrupamentos, representados na posição da figura onde seria a praia subaérea: Grupo 1, na porção inferior da figura 6, com estágio refletivo; Grupo 2 na maior parte da figura, que pode abranger todos os estágios intermediários e o estágio dissipativo; e o Grupo 3, na porção central e superior da figura 6 , sobre os estágios intermediários banco e cava longitudinal (BCL) e banco e praia de cúspides (BPC), onde são recorrentes.

Ressalta-se que nenhuma praia de enseada analisada neste trabalho abrange todo o modelo esquemático e sim que todas as praias analisadas podem ser inseridas dentro de um segmento do referido modelo esquemático. Por exemplo, as praias do Grupo 1, representado pela praia de Canasvieiras (perfis 1 a 4), 
se situam na porção mais abrigada da enseada, junto ao estágio refletivo. Já as praias dos Ingleses (perfis 8 a 13) e do Pântano do Sul (perfis 35 a 37), pertentes ao Grupo 2, podem variar de intermediária terraço de baixa mar (TBM) a intermediária banco e praia de cúspide (BPC). Nas praias Brava (perfis 5 a 7) e da Solidão (perfis 38 a 40), de pequena extensão e pertencentes ao Grupo 2, não há zona de baixa energia, e os estágios variam de bancos transversais (BT) a banco e praia de cúspides (BPC).

Rumando em direção a porção superior do modelo de estágios morfodinâmicos de praias de enseada (Fig. 6) podem se inserir praias com maior energia hidrodinâmica, tanto do Grupo 2 quanto do Grupo 3. A linha de corte em 7 no dendrograma (item 4,1), embora não tenha sido utilizada para compartimentação, distingue a maior parte das praias do Grupo 2 de alta energia das de baixa energia. A praia do Santinho (perfis 14 a 16), por exemplo, embora tenha pequena extensão, está su- jeita a alta energia, podendo gradar de intermediária com banco e praia de cúspide (BPC) a uma praia dissipativa. No entanto a praia que mais abrange espacialmente o modelo é o sistema praial Moçambique-Barra da Lagoa (perfis 17 a 21), que apresenta variabilidade granulométrica e hidrodinâmica, podendo gradar num mesmo momento desde uma praia intermediária com terraço de baixa mar (TBM) no extremo sul, junto a Barra da Lagoa até uma praia intermediária com banco e cava longitudinal (BCL) na porção norte da mesma. Outra praia que apresenta uma sequência de estágios num mesmo arco é a praia da Armação (perfis 27 a 34), cuja maior destes situa-se no Grupo 3, que também apresenta gradação na granulometria e na energia hidrodinâmica. Nesta as praias podem oscilar de intermediária com terraço de baixa mar (TBM) a intermediária com banco e cava longitudinal (BCL), mas com a presença de areias grossas a face da praia pode se comportar como refletiva de alta energia.
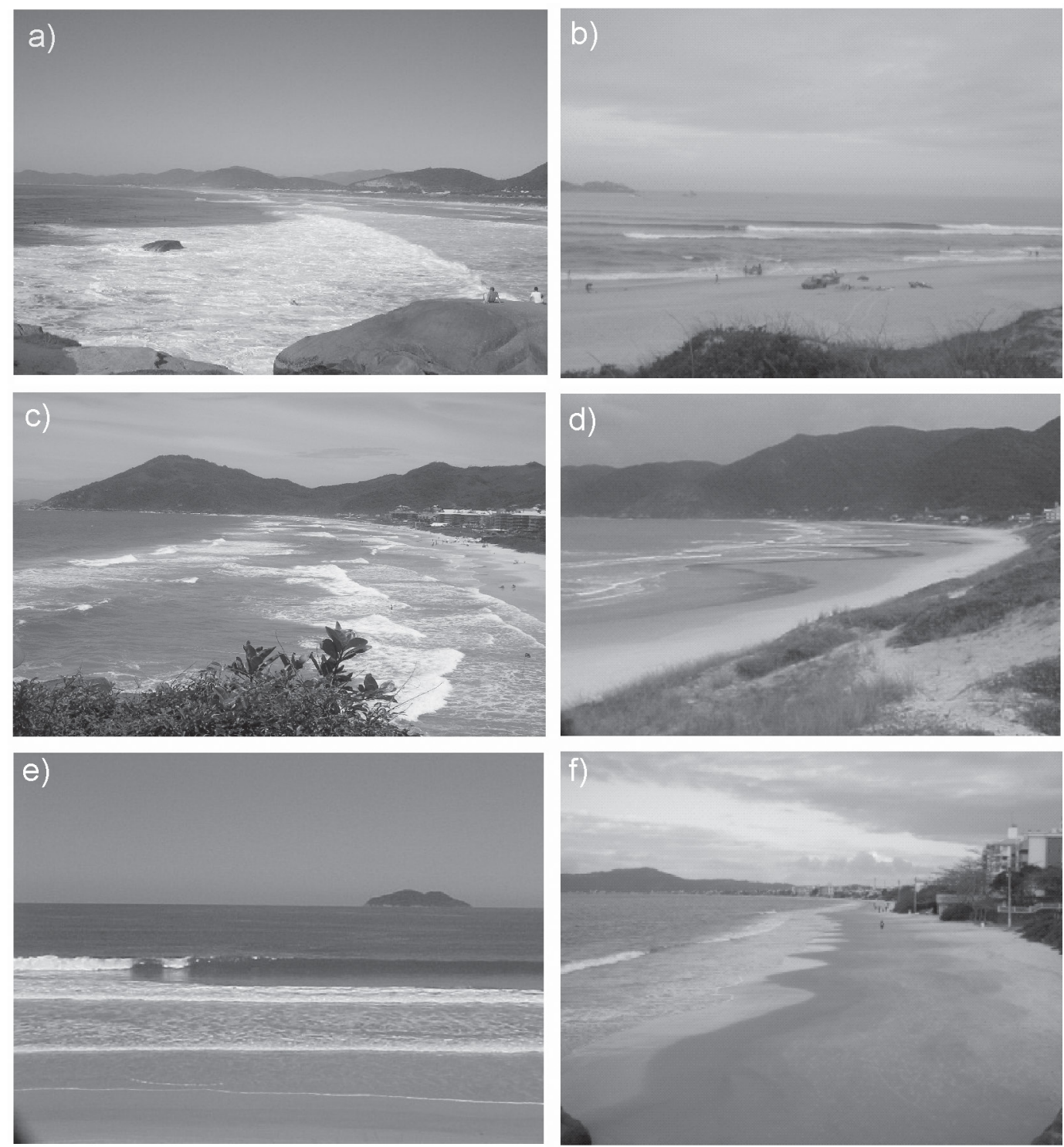

Figura 5. Estágios morfodinâmicos encontrados na costa oceânica da Ilha de Santa Catarina. A) dissipativo - Praia da Joaquina - P22; B) intermediário com banco e cava longitudinal - Praia do Campeche - P24; C) intermediário com banco e praia de cúspide - Praia Brava P5; D) intermediário com bancos transversais - Praia dos Açores - P37; E) intermediário com terraço de baixa mar - Praia do Pântano do Sul - P35; F) refletivo - Praia de Canasvieiras - P1. 


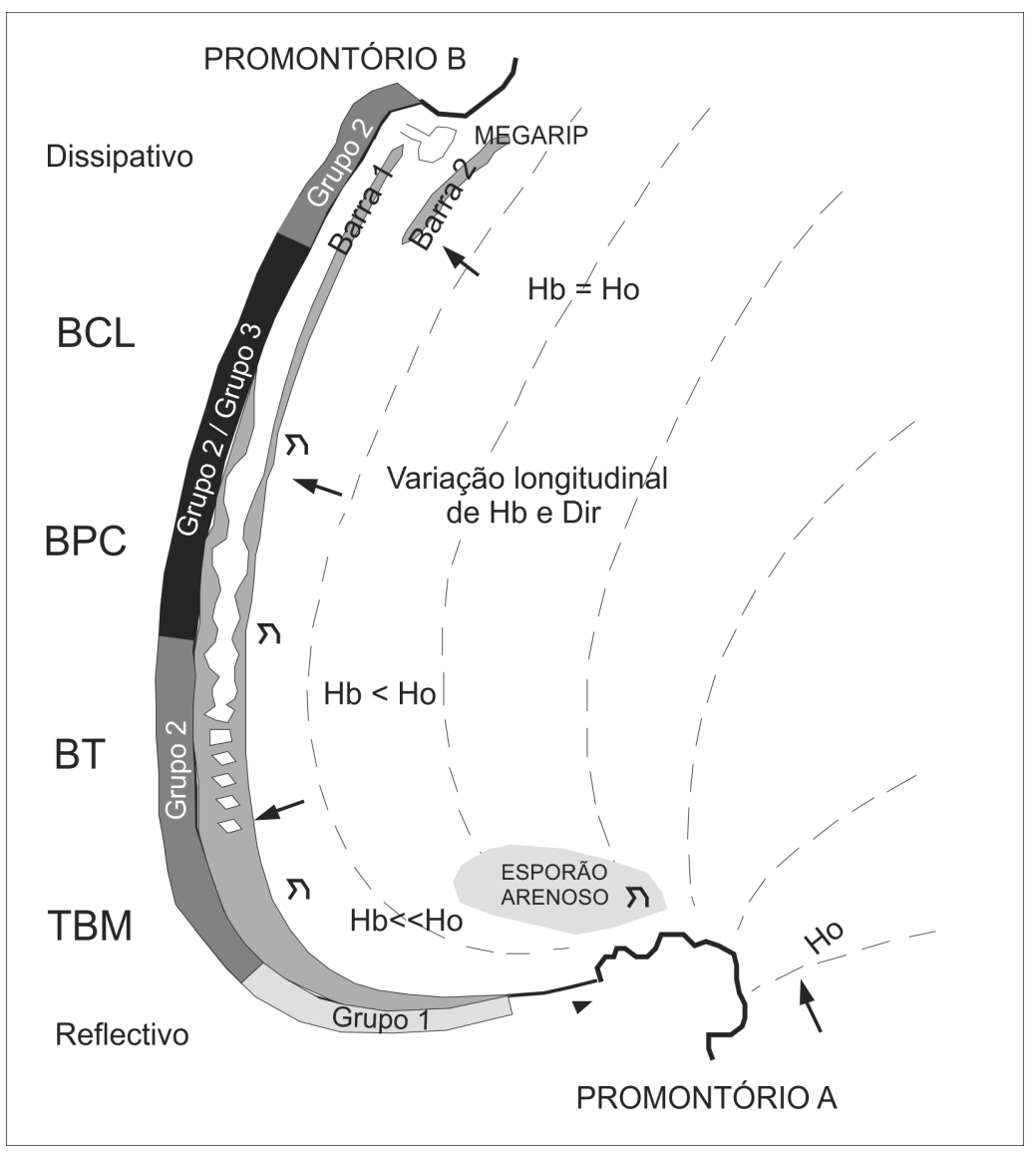

Figura 6. Esquema de variação tridimensional da topografia de uma praia de enseada, com a posição mais recorrente dos estágios morfodinâmicos (dissipativo; intermediário com banco e cava longitudinal - BCL; intermediário com banco e praia de cúspide - BPC; intermediário com bancos transversais - BT; intermediário com terraço de baixa mar - TBM; refletivo) e posição dos três grupos de praia encontrados na costa oceânica de Ilha de Santa Catarina (Grupo 1, Grupo 2 e Grupo 3) (Modificado de Short, 1999).

\section{Conclusões}

A orla oceânica da Ilha de Santa Catarina é composta por diversas praias de enseada que ocorrem alternadas com promontórios rochosos e podem ser subdivididas em três grupos, segundo os parâmetros utilizados: (i) praias compostas de areia fina, abrigadas da alta energia das ondas pela presença de promontórios rochosos que apresenta estágio morfodinâmico refletivo de baixa energia; (ii) praias compostas de areia fina expostas à moderada e à alta energia das ondas, que podem apresentar todos os estágios morfodinâmicos intermediários e o estágio dissipativo; e (iii) praias compostas de areia grossa, expostas à moderada e à alta energia das ondas, que apresentam características de praia intermediária se considerada a morfologia dos bancos, apresentando banco e cava longitudinal e banco e praia de cúspide, e o grau de exposição, com moderada a alta energia na zona de surfe, mas com face da praia refletiva.

Esta sistematização sinaliza tendências, visto que a variabilidade morfológica destas praias é forçada por processos que ocorrem em diversas escalas espaço-temporais em cada trecho analisado, destacando-se os processos de transporte transversal à linha de costa, com períodos de erosão e deposição, associados a alta e a baixa energia hidrodinâmica sobre cada setor, e o processo de rotação de praia, que transporta sedimentos lateralmente a costa, o qual predomina em praias mais expostas a ondulações e vagas provenientes de distintas direções, e que resulta num transporte residual, e dos estágios morfodinâmicos, para os extremos da praia. No entanto mostra que o modelo sequencial de evolução morfológica utilizado por diversos trabalhos anteriores, e por este trabalho numa análise de síntese, mesmo com todas as suas variações e evoluções, se adapta para a classificação das praias arenosas oceânicas da Ilha de Santa Catarina. Os 40 perfis de praia analisados também puderam ser introduzidos no modelo esquemático para praias de enseada.

Já os métodos estatísticos cumpriram o papel de auxiliar na interpretação de um grande número de dados. As análises de cluster e de análise de componentes principais mostraram-se eficientes para analisar praias de enseada, as quais têm significativas variações no grau de exposição, na granulometria e na variabilidade morfológica, sendo complementares. As estatísticas não paramétricas mostraram-se eficientes para sintetizar as características morfodinâmicas do grande número de diferentes praias existentes na Ilha, devolvendo resultados positivos em relação ao grau de exposição destas praias, o tamanho de grão e a respectiva conformação morfodinâmica que estas praias assumem. 
Agradecimentos - Gostaríamos de agradecer a Janete Abreu de Castilhos, Paulo César Leal, Kátia Regina Faraco, Maurício de Carvalho Torronteguy, Janice Resende Vieira Peixoto e Fábio Nor Guttler por não se oporem à reutilização de seus dados, apresentados em suas monografias, dissertações e/ ou teses de doutorado. A Jarbas Bonetti, Carla Bonetti e Gibran Teixeira pelos ensinamentos em estatística. A CAPES pela bolsa de doutorado ao primeiro autor.

\section{Referências}

Abreu de Castilhos, J. 1995. Estudo evolutivo, sedimentológico e morfodinâmico da Praia da Armação, Ilha de Santa Catarina. Florianópolis, 134p. Dissertação de Mestrado, Programa de Pós-Graduação em Geografia, Universidade Federal de Santa Catarina.

Araújo, C.E.S., Franco, D., Melo Filho, E. \& Pimenta, F. 2003. Wave regime characteristics of southern Brazilian coast. In: INTERNATIONAL CONFERENCE ON COASTAL AND PORT ENGINEERING IN DEVELOPING COUNTRIES, COPEDEC, 6. 2003, Colombo, Sri Lanka, Anais... Colombo, n. $97,15 \mathrm{p}$.

Baba, J. \& Komar, P.D. 1981. Measurements and analysis so settling velocities of natural quartz sand grains. Journal of Sedimentary Petrology, 51: 631-640.

Calliari, L.J., Muehe, D., Hoefel, F.G. \& Toldo JR, E.E. 2003. Morfodinâmica praial: uma breve revisão. Revista Brasileira de Oceanografia, 50: 63-78.

Caruso Jr., F. 1993. Mapa geológico da Ilha de Santa Catarina - Escala 1: 100.000. Texto explicativo e mapa. Notas Técnicas, 6: 1-28.

CECCA. CENTRO DE ESTUDOS CULTURA E CIDADANIA. 1997. Uma cidade numa ilha: relatório sobre os problemas socioambientais da Ilha de Santa Catarina. Florianópolis: Editora Insular, 248p.

Dean, R.G. 1973. Heuristic models of sand transport in the surf zone. Conference on Engineering dynamics in the surf zone. Proceedings..., Sydney, Austrália, p. 208-214.

Faraco, K. 2003. Comportamento morfodinâmico e sedimentológico da Praia dos Ingleses, Ilha de Santa Catarina - SC, durante o período de 1996 - 2001. Florianópolis, 120p. Dissertação de Mestrado, Programa de Pós-Graduação em Geografia, Universidade Federal de Santa Catarina.

Gibbs, R.J., Matthews, M.M. \& Link, D.A. 1971. The relationship between shere size and setting velocity. Journal of Sedimentary Petrology, 41(1): 7-18.

Guttler, F.N. 2006. Estudo morfodinâmico e granulométrico da praia do Rio das Pacas - Florianópolis (SC). Florianópolis, 101p. Trabalho de Graduação em Geografia, Universidade do Estado de Santa Catarina.

Klein, A.H.F. 2004. Morphodynamics of headland-bay beaches: examples from the coast of Santa Catarina State, Brazil. Faro, 198p. Tese de Doutorado. Faculdade de Ciências do Mar e do Ambiente. Universidade do Algarves.

Klein, A.H.F. \& Menezes, J.T. 2001. Beach morphodynamics and profile sequence for a headland bay coast. Journal of Coastal Research, 17(4): 812-835.

Landim, P.M.B. 2000. Análise estatística de dados geológicos multivariados. Lab. Geomática, DGA, IGCE, UNESP/Rio Claro, Texto didático, v. 3, 128 p. Disponível em: <http:// www.rc.unesp.br/igce/aplicada/DIDATICOS/LANDIM/ multivariados.pdf>. Acesso em: 5 jun. 2013.

Leal, P.C. 1999. Sistema praial Moçambique - Barra da Lagoa, Ilha de Santa Catarina, SC, Brasil: aspectos morfológicos, morfodinâmicos, sedimentológicos e ambientais. Florianópolis, 125p. Dissertação de Mestrado, Programa de Pós-Graduação em Geografia, Universidade Federal de Santa Catarina.

Mariotti, M.T. \& Franco, D. 2001. Análise ARIMA da resposta do nível do mar a forçantes atmosféricas locais. In: SEMINÁRIO SOBRE ONDAS, MARÉS E ENGENHARIA OCEÂNICA, 4, 2001, Arraial do Cabo, RJ. Anais... Arraial do Cabo, p. 21-22.

Melo Filho, E. 1991. Projeto Sentinelas do Mar: instruções para efetuar as observações. COPPE, Universidade Federal do Rio de Janeiro. Rio de Janeiro, 11 p.

Nimer, E. 1989. Climatologia da Região Sul. Revista Brasileira de Geografia, 34(1): 142-154.

Oliveira, U.R. 2004. Comportamento morfodinâmico e granulometria do arco praial Pântano do Sul - Açores, Ilha de Santa Catarina, SC, Brasil. Florianópolis, 102p. Dissertação de Mestrado, Programa de Pós-Graduação em Geografia, Universidade Federal de Santa Catarina.

Oliveira, U.R., Ribeiro, D.R., Horn Filho, N.O., Barletta, R.C. 2008a. Aspectos morfodinâmicos do sistema praial Canasvieiras - Cachoeira do Bom Jesus, norte da Ilha de Santa Catarina, Santa Catarina, Brasil. In: CONGRESSO BRASILEIRO DE OCEANOGRAFIA E CONGRESSO IBERO-AMERICANO DE OCEANOGRAFIA, 3, Fortaleza. 1 CD.

Oliveira, U.R., Barletta, R.C., Peixoto, J.R.V. \& Horn Filho, N.O. 2008b. Variabilidade morfológica da Praia do Pântano do Sul, Ilha de Santa Catarina, Brasil. Revista Brasileira de Geociências, 38(3): 566-576.

Peixoto, J.R.V. 2005. Análise morfossedimentar da Praia do Santinho e sua relação com a estrutura e dinâmica da vegetação "pioneira" da duna frontal, Ilha de Santa Catarina, SC, Brasil. 2005. Florianópolis, 78p. Dissertação de Mestrado, Programa de Pós-Graduação em Geografia, Universidade Federal de Santa Catarina.

Pereira, P.S. 2005. Variabilidade da orla oceânica do Rio Grande do Sul e suas implicações na elaboração de planos de contingência: aspectos morfodinâmicos, sedimentológicos e geomorfológicos. Rio Grande, 160p. Dissertação de Mestrado, Programa de Pós-Graduação em Oceanografia Física, Química e Geológica. Universidade Federal do Rio Grande.

Shapiro, S.S. \& Wilk, M.B. 1965. An analysis of variance test for normality (complete sample). Biometrika, 52(3): 591611.

Schweitzer, A. 2007. Comportamento morfossedimentar do arco praial e evolução do uso do solo na Praia Brava, Ilha de Santa Catarina, SC, Brasil. Florianópolis, 79p. Trabalho de Graduação em Geografia, Universidade Federal de Santa Catarina.

Simó, D.H. 2003. Caracterização e distribuição espacial das "ressacas" e áreas de risco na Ilha de Santa Catarina, SC, Brasil. Florianópolis, 130p. Trabalho de Graduação em Geografia, Universidade Federal de Santa Catarina.

Short, A.D. 1999. Beaches. In: Short, A.D. (Ed.) Handbook of beach and shore face morphodynamics. Chichester, p. 1-19.

Short, A.D. \& Hesp, P.A. 1982. Wave, beach and dune interactions in southeastern Australia. Marine Geology, 48: 259284.

Short, A.D. \& Masselink, G. 1999. Embayed and structurally controlled beaches. In: SHORT, A.D. (Ed.) Handbook of beach and shoreface morphodynamics. Chichester, p. 230249.

Tomazzoli, E.R., Oliveira, U.R. \& Horn Filho, N.O. 2007. Pro- 
veniência dos minerais de óxidos de Fe-Ti nas areias da Praia do Pântano do Sul, Ilha de Santa Catarina (SC), sul do Brasil. Revista Brasileira de Geofísica, 25: 49-64.

Torronteguy, M.C. 2002. Sistema praial Joaquina-Morro das Pedras e praias adjacentes da Costa Leste da Ilha de Santa Catarina: aspectos morfodinâmicos, sedimentológicos e fatores condicionantes. 2002. Florianópolis, 158p. Dissertação de Mestrado, Programa de Pós-Graduação em Geografia, Universidade Federal de Santa Catarina.

Trucollo, E.C. 1998. Maré meteorológica e forçantes atmosféricas locais em São Francisco do Sul - SC. 1998. Florianópolis, 100p. Dissertação de Mestrado, Programa de Pós-graduação em Engenharia Sanitária e Ambiental,
Universidade Federal de Santa Catarina.

Valentim, J.L. 2000. Ecologia numérica: uma introdução à análise multivariada de dados ecológicos. Rio de Janeiro: Editora Interciência, 117 p.

Wright, L.D. \& Short, A.D. 1984. Morphodynamics variability of surf zones in Australia. In: Komar (Ed.). Handbook of coastal processes and erosion. CRC Press, Boca Raton, Flórida, p. 35-64.

Wright, L.D., Short, A.D. \& Green, M.O. 1985. Short term changes in the morphodynamic states of beaches and surf zones: on empirical predictive model. Marine Geology, 62: 339-364.

Manuscrito 526.

Editor: Iran C. S. Corrêa. 
